\title{
COMPARAÇÃO DOS VALORES ESTIMADOS POR AMOSTRAGEM NA CARACTERIZAÇÃO DA ESTRUTURA DE UMA ÁREA DE FLORESTA NA AMAZÔNIA COM AS INFORMAÇÕES REGISTRADAS NO CENSO FLORESTAL ${ }^{1}$
}

\author{
Francisco José de Barros Cavalcanti², Sebastião do Amaral Machado ${ }^{3}$, Roberto Tuyuoshy Osokawa ${ }^{4}$ e \\ Ulisses Silva da Cunha ${ }^{5}$
}

\begin{abstract}
RESUMO - O objetivo deste trabalho foi comparar valores estimados obtidos por amostragem com os valores verdadeiros registrados no Censo Florestal (inventário 100\%) de uma área de floresta na Amazônia. Foi simulada uma amostragem sistemática, atendendo às exigências do IBAMA (BRASIL, 2007), com unidades amostrais de 2 ha e intensidade amostral de 14\% em uma área de 1.000 ha, que foi submetida a um Censo Florestal. Neste e na simulação do inventário florestal, consideraram-se apenas a população com DAP $\geq 40 \mathrm{~cm}$ e uma lista de 60 espécies que foram identificadas como a população de árvores consideradas de valor comercial. Foram avaliados os desvios da abundância, da área basal e do volume por hectare da amostragem em relação à população. Os desvios foram avaliados em relação às espécies individualmente e às espécies agrupadas, de acordo com a classificação de preço utilizada pelo Serviço Florestal Brasileiro. Também foram avaliados os desvios por classe de diâmetro, por grupo e para o total da população. Mesmo com intensidade amostral de 14\%, seis espécies (10\%) não foram registradas na amostra, resultando em desvios de $614 \%$ para mais e $100 \%$ para menos em relação à abundância, à área basal e ao volume.
\end{abstract}

Palavras-chave: Inventário florestal, Intensidade amostral e Exatidão.

\section{COMPARISON OF VALUES ESTIMATED BY SAMPLING TO CHARACTERIZE THE STRUCTURE OF A FOREST AREA IN THE AMAZON BASED ON THE INFORMATION REGISTERED IN THE FORESTRY CENSUS}

\begin{abstract}
The aim of this work was to compare the estimated values obtained by sampling with the actual values recorded in the Forest Census (inventory 100\%) of a forest area in the Amazon. A systematic sampling was simulated, attending the requirements of IBAMA, with 2-ha sample units and sampling intensity of $14 \%$ in a 1,000-ha area, which was subjected to a forestry census. The census and simulation of forest inventory considered only the population with $\mathrm{DBH} \geq 40 \mathrm{~cm}$ and a list of 60 species which were identified as the population of trees considered of commercial value. It was evaluated the deviations of abundance, basal area and volume per hectare of sampling in relation to population. Deviations were evaluated with respect to individual species and species grouped according to the classification of price used by the Brazilian Forest Service. Deviations were also evaluated by diameter class, by group, and the total population. Even with sampling intensity of $14 \%$, six species (10\%) were not recorded in the sample, resulting in deviations from more than $614 \%$ to more and $100 \%$ to less in relation to abundance, basal area and volume.
\end{abstract}

Keywords: Forest inventory, Sampling intensity and Accuracy.

\footnotetext{
${ }^{1}$ Recebido em 06.05.2010 e aceito para publicação em 02.05.2011.

${ }^{2}$ Departamento de Ciências Florestais, Universidade Federal do Amazonas. E-mail: <fjbcavalcanti@gmail.com>.

${ }^{3}$ Universidade Federal do Paraná, Curso de Engenharia Florestal, Departamento de Ciências Florestais. E-mail: <samachado@ufpr.br> .

${ }^{4}$ Universidade Federal do Paraná, Curso de Engenharia Florestal, Departamento de Ciências Florestais. E-mail: <rth@onda.com.br>.

${ }^{3}$ Departamento de Ciências Florestais, Universidade Federal do Amazonas. E-mail: <ulisses@ufam.edu.br>.
} 


\section{INTRODUÇÃO}

O conhecimento da composição florística e da estrutura da floresta permite o planejamento e estabelecimento de sistemas de manejo com produção sustentável (SOUZA et al., 2006).

A Norma de Execução n ${ }^{\circ} 01$ de 2007, do IBAMA, estabeleceu a obrigatoriedade da execução de inventários florestais por amostragem em planos de manejo na Amazônia. A mesma norma também estabelece que o inventário deva apresentar média para abundância, área basal e volume das espécies comerciais, a partir do diâmetro comercial, com precisão mínima de 10\% e com $95 \%$ de probabilidade de que a média verdadeira não ultrapasse o limite do erro amostral.

A exatidão de uma medida refere-se à maior ou menor aproximação dela com a medida verdadeira, e a precisão em mensuração florestal expressa o grau de aproximação de uma série de medidas em relação à média das medidas, ou o grau de concordância entre valores da série (HUSCH et al., 1972 apud MACHADO; FIGUEIREDO FILHO, 2003). Portanto, tanto a exatidão quanto a precisão são importantes parâmetros a serem avaliados na estimativa de uma variável da floresta.

Vários trabalhos foram realizados na Amazônia sobre métodos e processos de amostragem de florestas para avaliações quantitativa e estrutural, como os de Queiroz (1977), Silva (1980), Higuchi et al. (1982), Queiroz (1984)e Higuchi (1987). Entretanto, esses autores trabalharam com populações a partir de 15, 20 ou 30 cm de DAP. Considerando o J invertido característico da estrutura vertical da floresta, com abundância decrescente de indivíduos de maiores diâmetros e número menor de espécies comerciais do que o total das espécies, é provável que a amostra recomendada pelos autores citados não seja adequada para o cumprimento da Norma de Execução do IBAMA nº. 1, de 2007 (BRASIL, 2007).

Soares et al. (2009), comparando procedimentos de amostragem para espécies florestais raras com padrão de distribuição agregado, observaram tendência de diminuição de erro de amostragem com o aumento do tamanho de amostra em todos os procedimentos utilizados.

Machado (1988) avaliou especificamente a exatidão de um inventário amostral na estimativa de volume e de abundância das espécies comerciais com DAP $\geq 55 \mathrm{~cm}$, numa área onde o censo florestal foi realizado em mais de três mil hectares. Após comparar os valores estimados pelo inventário que foi realizado com $1,43 \%$ de intensidade, utilizando unidades de amostra de 15 x 250 m, o autor concluiu que o inventário por amostragem não foi adequado para a estimativa da abundância e do volume das espécies comerciais. Os desvios variaram entre sete e $100 \%$. Das 30 espécies selecionadas, apenas cinco apresentaram erro menor do que $20 \%$, e, entre as cinco espécies mais abundantes na área, duas tiveram desvio maior do que $20 \%$ entre a estimativa e o parâmetro verdadeiro da floresta.

Entre as atribuições do Serviço Florestal Brasileiro, criado por meio da Lei 11.284, de 2 de março de 2006, constam promover e gerenciar a concessão das florestas públicas. O Decreto 3.036, de 2006, estabelece que as concessões se deem por licitação, em que a proposta vencedora será aquela que maior pontuação obtiver no preço ofertado pelos produtos florestais a serem explorados e nos benefícios sociais e ambientais compromissados.

O Serviço Florestal Brasileiro reuniu as espécies florestais comerciais da Amazônia em quatro grupos distintos, com um preço padronizado para cada grupo (BRASIL, 2007). Cavalcanti et al. (2009) testaram oito comprimentos diferentes de unidades de amostra de 50 m de largura e concluíram que, entre os tamanhos testados, o de $400 \mathrm{~m}$ foi o mais adequado para atendimento das exigências da Norma de Execução nº 01/2007 do IBAMA, incluindo as árvores da classe de diâmetro imediatamente inferior à comercial.

Este trabalho teve como objetivo comparar valores verdadeiros obtidos do Censo Florestal com os valores estimados através da amostragem, na estimativa da abundância, da área basal e do volume por espécie isoladamente e por grupo de espécies, de acordo com a classificação do Serviço Florestal Brasileiro, para cada classe de diâmetro.

Essa comparação é relevante, uma vez que informações mais acuradas acerca do potencial da floresta embasarão melhor as ofertas aos lotes de concessão florestal ou, no caso de comprovada a falta de exatidão na estimativa dos volumes e valores, o questionamento do nível de exigência legal atual. 


\section{MATERIAL E MÉTODOS}

A área do estudo localizava-se ao Norte do Município de Sena Madureira, AC. Nela foi realizado o Censo Florestal em 1.000 hectares, subdivididos em 10 Unidades de Trabalho de 100 ha cada uma. O centro da área de estudo possuía as seguintes coordenadas geográficas: $9^{\circ} 26^{\prime} 32^{\prime \prime}$ de latitude Sul e 68 $8^{\circ} 38^{\prime}$ 22" de longitude à Oeste de Greenwich. A vegetação da área era constituída principalmente por Floresta Ombrófila Aberta de Terras Baixas com bambus em associação com Floresta Ombrófila Densa Terras Baixas com Dossel emergente.

Para a realização do Censo Florestal, ou inventário a $100 \%$, foram abertas picadas paralelas na direção norte-sul, distantes 50 m entre si. Em cada picada foram colocadas balizas a cada $25 \mathrm{~m}$, com a respectiva metragem em relação à origem, para posterior registro das coordenadas y de cada árvore. A coordenada x de cada árvore foi obtida por meio do número da picada e da distância de cada árvore em relação a ela. A população considerada no estudo foi a de árvores com DAP $\geq 40 \mathrm{~cm}$, de uma lista de 60 espécies consideradas comerciais por empresários locais. Nos 1.000 ha onde o Censo Florestal foi realizado, registraram-se 11.673 árvores das espécies consideradas. Essa população apresentou as médias de abundância de 11,67 árvores/ha, área basal de 4,04 $\mathrm{m}^{2} /$ ha e volume de $31,50 \mathrm{~m}^{3} / \mathrm{ha}$.

De acordo com Cavalcanti et al. (2009), a intensidade amostral necessária para atender à precisão exigida pelo IBAMA, de 10\% de erro de abundância, área basal e volume de árvores comerciais acima de $40 \mathrm{~cm}$ de DAP, com 95\% de probabilidade, deve ser de 12,8\%. Baseando-se nessa orientação, foram implantadas neste estudo, através de simulação, 70 unidades de amostra de 50 x 400 m, sistematicamente distribuídas na mesma área onde foi realizado o Censo Florestal, perfazendo uma intensidade amostral de $14 \%$ da área. O processo de amostragem adotado foi o sistemático, com 200 m de distância entre as unidades de amostra. Ele foi escolhido para garantir a distribuição das unidades amostrais em toda a área do estudo. De acordo com Queiroz (1998), a amostragem sistemática é mais eficiente quando se deseja mapear a floresta com relação à sua tipologia.

A identificação da presença das árvores das espécies consideradas comerciais na amostra foi realizada por meio de rotinas de processamento de dados do Microsoft Access, através do cruzamento das coordenadas x e y das árvores, registradas no Censo Florestal, com os limites de cada unidade de amostra.
As espécies comerciais registradas na floresta foram posteriormente agrupadas de acordo com a classificação do Serviço Florestal Brasileiro - SFB (BRASIL, 2007). Nessa classificação, as espécies são agrupadas, conforme seu valor comercial, em quatro grupos distintos. Os grupos, numerados de 1 a 4, possuem valores comerciais decrescentes.

Entre as 60 espécies registradas na área de estudo, 28 foram classificadas diretamente na lista do SFB. As espécies não encontradas nessa lista foram classificadas de acordo com o gênero. Esse foi o caso de 27 espécies. As cinco demais espécies comerciais, cujos gêneros não constaram na lista do SFB, foram incluídas no Grupo 3 quando destinadas à serraria e no Grupo 4 quando destinadas à laminadora. Dessa forma, foram classificadas cinco espécies no Grupo 1, 14 no Grupo 2, 21 no Grupo 3 e 20 no Grupo 4.

Para comparação da estrutura da população registrada no Censo Florestal com a estimada através da amostragem, as árvores foram organizadas por espécie e por classes de $10 \mathrm{~cm}$ de diâmetros até o DAP $<150 \mathrm{~cm}$. A partir desse diâmetro, todas as árvores foram reunidas numa única classe.

Foi calculado o intervalo de confiança da média da abundância, da área basal e do volume amostral, num nível de 5\% de significância. No mesmo nível de significância foi realizada a avaliação da diferença entre a média da amostra e a média da população, por meio do teste $\mathrm{T}$ das três variáveis estudadas (abundância, área basal e volume), de acordo com Zar (1999).

O número de espécies identificados na amostra por grupo comercial foi comparado com o existente na população e analisado com o teste do Qui-quadrado, conforme Vieira (2008), também com 5\% de significância. Também foram analisados os desvios de abundância, a área basal e o volume por espécie e por grupo de comercialização, bem como por classe de diâmetro entre a população registrada no Censo Florestal e a respectiva estimativa, obtida através da simulação do inventário por amostragem, a fim de averiguação da sua exatidão.

\section{RESULTADOS}

A análise estatística do inventário amostral da área é apresentada na Tabela 1. A intensidade amostral de $14 \%$ da área garantiu erros amostrais relativos para a abundância, área basal e volume menores do que 10\%, 
Tabela 1 - Resultados do inventário florestal por amostragem e análise estatística.

Table 1 - Results of forest inventory by sampling and statistical analysis.

\begin{tabular}{lccc}
\hline & Abundância(árvores) & Área basal $\left(\mathrm{m}^{2}\right)$ & Volume $\left(\mathrm{m}^{3}\right)$ \\
\hline Média da população (2 ha) & 23,35 & 8,08 & 63,01 \\
Média da amostra (2 ha) & 24,82 & 8,39 & 65,71 \\
Erro-padrão da média corrigido* & 1,12 & 0,35 & 2,77 \\
Erro amostral absoluto (T (6;0,05 $\left.^{*}=1,9946\right)$ & 2,24 & 0,69 & 5,53 \\
Erro amostral relativo (em \%) & 9,02 & 8,24 & 8,42 \\
Limite inferior da média (u.a.) & 22,59 & 7,70 & 60,17 \\
Limite superior da média (u.a.) & 27,07 & 9,08 & 71,24 \\
Dimensionamento da amostra (n) & 59 & 50 & 52 \\
Dimensionamento da amostra (\%) & 11,80 & 10,00 & 10,40 \\
Coeficiente de variação (\%) & 40,78 & 37,25 & 38,09 \\
\hline
\end{tabular}

${ }^{*}$ Erro-padrão da média para cálculo do intervalo de confiança, corrigido para a população finita.

que é o limite estabelecido pela legislação. O maior erro amostral relativo foi o da abundância (9,02\%), que significou também o maior dimensionamento da amostra, que foi de 59 unidades de amostra de 2 ha. $O$ teste $\mathrm{T}$ para uma amostra, indicado por Zar(1984), que comparou a abundância, a área basal e o volume da amostra com a população, apresentou, respectivamente, $T$ calculados de 1,23; 0,83; e 0,90, sendo todos abaixo do T tabelado de 1,9946.

Uma vez constatado que a amostra foi suficiente para garantir a precisão dentro do limite preestabelecido pela norma legal, foi dado prosseguimento à análise. A Tabela 2 apresenta a relação entre o número de espécies por grupo (de acordo com a classificação do Serviço Florestal Brasileiro) na população e na amostra. Os dois grupos de maior valor representaram 35,19 e 33,33\% das espécies da população e da amostra, respectivamente. Ficando os dois grupos de espécies menos valiosas responsáveis por 79,93 e 66,67\% das espécies da população e da amostra, também respectivamente. Seis espécies, ou 10\% do número de espécies da população comercial, não foram registradas na amostragem. As diferenças entre

Tabela 2 - Número de espécies por grupo na população e na amostra.

Table 2 - Number of species by group in the population and in the sample.

\begin{tabular}{ccc}
\hline Grupo & População & Amostra \\
\hline 1 & 5 & 4 \\
2 & 14 & 14 \\
3 & 21 & 18 \\
4 & 20 & 18 \\
\hline Total & 60 & 54 \\
\hline
\end{tabular}

a amostra e a população não foi considerada significativa pelo teste do Qui-Quadrado no nível de 5\% de significância $\left(\mathrm{X}_{\text {calculado }}^{2}=0,829\right.$ e $\left.\mathrm{X}_{\text {tabelado }}^{2}=7,815\right)$.

Na Tabela 3, apresentam-se os desvios da estimativa da abundância, da área basal e do volume por espécie da amostra em relação à população. Nela, pôde-se observar que os desvios variaram de $100,00 \%$ negativos, quando as espécies da área não foram registradas pelo inventário amostral (esse foi o caso de Aniba canelilla, Calophyllum brasiliense, Cariniana estrellensis, Piptadenia sp., Simarouba amara e Stryphnodendron sp.), até 614,29 positivos, quando a espécie apareceu proporcionalmente mais na amostragem do que na população (caso de Hymenolobium sp.). Vale salientar que a partir de 25 unidades de amostra, 50 das 60 espécies haviam sido registradas, e com 70 unidades de amostra, isto é, mais do dobro de intensidade amostral, apenas quatro espécies foram adicionadas.

Na Tabela 4, apresentam-se os desvios de abundância, área basal e volume com relação aos grupos de comercialização. O desvio maior foi de 10,66\% de abundância no Grupo 4 . O menor foi o de 2,33\% da área basal no Grupo 1.

Considerando os desvios por grupo, no Grupo 1 a subestimação foi menor que 4\%. O Grupo 2 apresentou a maior superestimação no volume, que foi de 8,47\%. No Grupo 3, todos os valores foram superestimados, sendo a máxima de 5,04\% para a área basal. Com exceção do Grupo 1, cujo desvio relativo da abundância foi de $-3,68 \%$, os desvios foram sempre positivos, isto é, superestimaram os valores reais. Os desvios relacionados à área basal apresentaram-se mais uniformemente distribuídos do que os da abundância.

Revista Árvore, Viçosa-MG, v.35, n.5, p.1061-1068, 2011 
Tabela 3 - Desvios da estimativa da abundância, área basal e volume por espécie em relação à população real.

Table 3 -Deviations of the estimate of the abundance, basal area and volume by species in relation to the real population.

\begin{tabular}{|c|c|c|c|c|c|c|c|}
\hline \multirow[t]{2}{*}{ Espécie } & \multirow[t]{2}{*}{ G } & \multicolumn{2}{|c|}{ Abundância } & \multicolumn{2}{|c|}{ Área basal } & \multicolumn{2}{|c|}{ Volume } \\
\hline & & $\mathrm{D}$ & $\mathrm{D}(\%)$ & $\mathrm{D}$ & $\mathrm{D}(\%)$ & $\mathrm{D}$ & $\mathrm{D}(\%)$ \\
\hline Agonandra brasiliensis & 2 & 0,02 & 10,50 & 0,01 & 17,80 & 0,07 & 18,56 \\
\hline Amburana acreana & 1 & $-0,09$ & $-25,47$ & $-0,03$ & $-26,45$ & $-0,26$ & $-26,77$ \\
\hline Anacardium giganteum & 4 & 0,00 & $-10,71$ & 0,01 & 49,73 & 0,05 & 64,20 \\
\hline Aniba canelilla & 1 & 0,00 & $-100,00$ & 0,00 & $-100,00$ & $-0,01$ & $-100,00$ \\
\hline Apuleia molaris & 2 & $-0,02$ & $-4,76$ & 0,02 & 10,10 & 0,33 & 16,89 \\
\hline Aspidosperma macrocarpon & 2 & $-0,01$ & $-52,38$ & $-0,01$ & $-81,61$ & $-0,04$ & $-85,18$ \\
\hline Aspidosperma sp. & 2 & 0,00 & $-0,24$ & 0,00 & $-2,27$ & $-0,02$ & $-4,99$ \\
\hline Astronium lecointei & 2 & 0,05 & 12,78 & 0,01 & 6,05 & 0,03 & 3,43 \\
\hline Brosimum sp. & 3 & $-0,01$ & $-2,60$ & $-0,01$ & $-3,99$ & $-0,03$ & $-2,96$ \\
\hline Calophyllum brasiliense & 3 & 0,00 & $-100,00$ & 0,00 & $-100,00$ & 0,00 & $-100,00$ \\
\hline Cariniana estrellensis & 3 & 0,00 & $-100,00$ & 0,00 & $-100,00$ & 0,00 & $-100,00$ \\
\hline Cariniana sp. & 3 & $-0,01$ & $-21,88$ & $-0,01$ & $-27,35$ & $-0,06$ & $-24,30$ \\
\hline Cassia sp. & 4 & $-0,01$ & $-35,06$ & 0,00 & $-23,44$ & $-0,02$ & $-29,06$ \\
\hline Castilla ulei & 4 & 0,11 & 16,86 & 0,02 & 12,91 & 0,12 & 12,35 \\
\hline Cedrela odorata L. & 1 & 0,01 & 3,81 & 0,00 & $-1,79$ & 0,00 & $-0,59$ \\
\hline Ceiba pentandra & 4 & 0,03 & 3,98 & 0,00 & $-1,31$ & 0,04 & 1,31 \\
\hline Ceiba samauma & 4 & $-0,03$ & $-9,40$ & $-0,03$ & $-22,67$ & $-0,21$ & $-23,26$ \\
\hline Celtis sp. & 4 & 0,02 & 217,46 & 0,00 & 190,49 & 0,02 & 189,66 \\
\hline Clarisia racemosa & 3 & 0,05 & 11,08 & 0,03 & 20,78 & 0,16 & 17,63 \\
\hline Copaifera sp. & 3 & $-0,03$ & $-22,78$ & $-0,01$ & $-11,29$ & $-0,08$ & $-13,28$ \\
\hline Cordia alliodora & 2 & 0,01 & 78,57 & 0,00 & 69,70 & 0,02 & 77,97 \\
\hline Couma macrocarpa & 4 & 0,06 & 76,25 & 0,02 & 97,79 & 0,17 & 101,58 \\
\hline Couratari sp. & 3 & 0,00 & 3,38 & 0,00 & 14,45 & 0,05 & 17,12 \\
\hline Dialium guianense & 3 & $-0,04$ & $-30,70$ & $-0,01$ & $-45,84$ & $-0,07$ & $-40,91$ \\
\hline Dipteryx odorata & 2 & $-0,01$ & $-52,38$ & 0,00 & 5,06 & 0,02 & 27,77 \\
\hline Ficus sp. & 4 & 0,02 & 20,39 & 0,00 & 9,98 & 0,04 & 13,88 \\
\hline Hura crepitans & 4 & 0,13 & 15,52 & 0,01 & 2,02 & 0,06 & 1,43 \\
\hline Hymenaea courbaril & 2 & $-0,02$ & $-37,34$ & $-0,01$ & $-33,58$ & $-0,09$ & $-40,19$ \\
\hline Hymenaea oblongifolia & 2 & 0,00 & 4,76 & 0,00 & $-0,13$ & $-0,01$ & $-3,91$ \\
\hline Hymenolobium excelsum & 3 & $-0,01$ & $-57,98$ & 0,00 & $-73,37$ & $-0,03$ & $-68,85$ \\
\hline Hymenolobium sp. & 3 & 0,01 & 614,29 & 0,00 & 614,29 & 0,01 & 614,29 \\
\hline Manilkara huberi & 3 & 0,09 & 25,93 & 0,03 & 25,94 & 0,23 & 25,30 \\
\hline Mezilaurus itauba & 2 & $-0,02$ & $-29,97$ & $-0,01$ & $-40,36$ & $-0,05$ & $-39,21$ \\
\hline Micropholis melinoniana & 2 & 0,00 & $-0,79$ & 0,02 & 13,88 & 0,14 & 14,97 \\
\hline Minquartia guianensis & 3 & 0,01 & 38,89 & 0,00 & 37,18 & 0,02 & 46,33 \\
\hline Miroxylon balsamum & 3 & 0,01 & 2,04 & 0,00 & 2,86 & 0,02 & 2,08 \\
\hline Ocotea sp. & 2 & 0,01 & 6,93 & 0,00 & 10,73 & 0,03 & 8,79 \\
\hline Parkia paraensis & 4 & 0,00 & 19,05 & 0,00 & 18,43 & 0,01 & 36,40 \\
\hline Parkia sp. & 4 & $-0,05$ & $-35,52$ & $-0,02$ & $-34,86$ & $-0,15$ & $-31,86$ \\
\hline Phyllocarpus sp. & 3 & 0,03 & 7,57 & 0,01 & 10,71 & 0,11 & 11,08 \\
\hline Piptadenia sp. & 3 & 0,00 & $-100,00$ & 0,00 & $-100,00$ & $-0,01$ & $-100,00$ \\
\hline Pithecellobium sp. & 3 & $-0,04$ & $-21,82$ & $-0,02$ & $-27,37$ & $-0,15$ & $-34,19$ \\
\hline Platymiscium sp. & 2 & 0,01 & 25,31 & 0,00 & 0,54 & 0,02 & 15,29 \\
\hline Platymiscium trinitalis & 2 & 0,02 & 92,31 & 0,00 & 70,96 & 0,04 & 86,56 \\
\hline Pouteria sp. & 3 & 0,00 & 5,04 & 0,00 & $-18,89$ & $-0,03$ & $-19,86$ \\
\hline Pouteria sp. & 3 & 0,11 & 17,71 & 0,03 & 22,08 & 0,25 & 22,74 \\
\hline Protium sp. & 3 & 0,02 & 56,79 & 0,00 & 56,92 & 0,03 & 59,34 \\
\hline Pseudolmédia multinervis & 3 & 0,01 & 2,64 & 0,00 & 2,04 & 0,02 & 3,23 \\
\hline Pterocarpus amazonicus & 4 & 0,01 & 1,32 & 0,00 & $-3,82$ & $-0,03$ & $-4,63$ \\
\hline Qualea tesmanni & 4 & 0,01 & 6,03 & 0,00 & 10,06 & 0,05 & 12,46 \\
\hline Sapium marmieri & 4 & 0,14 & 17,38 & 0,03 & 12,60 & 0,20 & 12,54 \\
\hline Schizolobium amazonicum & 4 & 0,03 & 36,99 & 0,01 & 32,85 & 0,07 & 41,50 \\
\hline Simarouba amara & 4 & $-0,02$ & $-100,00$ & 0,00 & $-100,00$ & $-0,04$ & $-100,00$ \\
\hline Stryphnodendron sp. & 4 & $-0,01$ & $-100,00$ & 0,00 & $-100,00$ & $-0,01$ & $-100,00$ \\
\hline Swietenia macrophylla & 1 & 0,00 & 3,90 & 0,02 & 27,16 & 0,18 & 28,13 \\
\hline Tabebuia serratifolia & 1 & 0,04 & 18,50 & 0,00 & 9,09 & 0,02 & 5,58 \\
\hline Tecophilaea procera & 3 & $-0,02$ & $-71,43$ & 0,00 & $-72,07$ & $-0,02$ & $-74,24$ \\
\hline Terminalia sp. & 4 & 0,02 & 29,87 & 0,00 & 7,31 & 0,02 & 10,13 \\
\hline Terminalia sp. & 4 & 0,04 & 8,54 & 0,01 & 4,51 & 0,02 & 2,02 \\
\hline Vatairea sericea & 4 & 0,05 & 44,11 & 0,02 & 47,27 & 0,14 & 48,13 \\
\hline Total & & 0,74 & 6,35 & 0,15 & 3,83 & 1,35 & 4,28 \\
\hline Máximo & & 0,14 & 614,29 & 0,03 & 614,29 & 0,33 & 614,29 \\
\hline Mínimo & & $-0,09$ & $-100,00$ & $-0,03$ & $-100,00$ & $-0,26$ & $-100,00$ \\
\hline
\end{tabular}

$\overline{\mathrm{G}}=$ Grupo, $\mathrm{D}=$ Desvio absoluto e $\mathrm{D}(\%)=$ Desvio relativo. / $\mathrm{G}=$ Group, $\mathrm{D}=$ absolute deviation and $\mathrm{D}(\%)=$ relative deviation. 
Tabela 4 - Desvios da estimativa da abundância, área basal e volume por grupo de espécie em relação à população real. Table 4 -Deviations of the estimate of the abundance, basal area and volume by group of species in relation to the real population.

\begin{tabular}{cccccc}
\hline Grupo & & \multicolumn{2}{c}{ Variável } & \multicolumn{2}{c}{ Valores Desvios } \\
\cline { 3 - 5 } & & Verdadeiro & Estimado & Absoluto & Relativo (\%) \\
\hline \multirow{2}{*}{1} & Abundância & 0,96 & 0,93 & $-0,04$ & $-3,68$ \\
& Área basal & 0,33 & 0,32 & $-0,01$ & $-2,33$ \\
\multirow{2}{*}{2} & Volume & 2,58 & 2,51 & $-0,07$ & $-2,74$ \\
& Abundância & 1,80 & 1,86 & 0,06 & 3,35 \\
& Área basal & 0,66 & 0,71 & 0,04 & 8,43 \\
3 & Volume & 5,57 & 6,04 & 0,47 & 4,70 \\
& Abundância & 3,92 & 4,10 & 0,18 & 5,04 \\
& Área basal & 1,15 & 1,20 & 0,06 & 4,62 \\
4 & Volume & 8,92 & 9,33 & 0,41 & 3,66 \\
& Abundância & 5,00 & 5,53 & 0,53 & 3,71 \\
\hline \multirow{2}{*}{ Total } & Área basal & 1,90 & 1,96 & 0,06 & 6,35 \\
& Volume & 14,44 & 14,98 & 0,54 & 3,83 \\
& Abundância & 11,67 & 12,41 & 0,74 & 4,28 \\
\hline
\end{tabular}

Considerando o volume de madeira, o grupo que apresentou o maior desvio foi o Grupo 2, de 4,62\%. Novamente, as diferenças avaliadas pelo teste do QuiQuadrado não foram estatisticamente significativas no nível de 5\% de significância.

Finalmente, na Tabela 5 são apresentados os desvios absolutos e relativos por hectare das estimativas da abundância, da área basal e do volume, por classes de diâmetro, em relação à população real. Os maiores desvios estão nas classes de diâmetro superiores, destacando-se a classe com ponto médio de $135 \mathrm{~cm}$, cujos desvios relativos foram de 24,22\%, 23,00\% e 29,01\%, respectivamente, para abundância, área basal e volume.

Os maiores desvios são sempre do volume, ao mesmo tempo que os menores são sempre da abundância. Embora os desvios ocorram para maior e para menor, há certa predominância naqueles para maior em relação à população.

Entre 40 e $50 \mathrm{~cm}$ de DAP e 90 a $100 \mathrm{~cm}$ de DAP, os desvios também foram superiores a $10 \%$, sendo o desvio maior, o da abundância entre 40 e $50 \mathrm{~cm}$ de DAP, que chegou a $11,78 \%$.

\section{DISCUSSÃO}

Pôde ser constatado que, apesar da alta intensidade amostral, seis espécies, equivalentes a 10\% do total, não foram registradas na simulação do inventário florestal diagnóstico. Esse resultado está de acordo com o de
Machado (1988), que também constatou o mesmo problema na comparação entre o Censo Florestal e o inventário por amostragem da Floresta Nacional do Tapajós. Inventários por amostragem na Amazônia geralmente são realizados com baixa intensidade amostral, menos de 1\%, em função dos seus custos. Eles são utilizados apenas para se obter uma primeira informação da floresta a ser manejada (ARAÚJO, 2006). Com a obrigatoriedade do Censo Florestal ou inventário a 100\% para a autorização de planos de manejo na Amazônia, a partir de 1998 (BRASIL, 1998) o inventário diagnóstico passou a ser opção do empresário ou do engenheiro florestal responsável pelo plano de manejo, que levaria em consideração seus custos e benefícios. Entretanto, a partir de BRASIL (2006) houve retrocesso da legislação, com o retorno da obrigatoriedade do inventário diagnóstico, apesar da já existente obrigatoriedade do Censo Florestal. Essa contradição é agravada pelos níveis de exigência das normas de execução do IBAMA, a partir de 2007 (BRASIL, 2007).

O Censo Florestal foi adotado por algumas empresas da região antes de ser obrigatório pelo governo federal pela IN 6/1998 (BRASIL, 1998), em função dos benefícios financeiros que proporciona, advindos principalmente em razão da precisão e exatidão das informações por ele fornecidas. De um lado, a localização e as características de cada árvore na floresta possibilitam maior segurança nas execuções contratuais, quando os volumes são negociados por espécie. De outro lado, a localização

Revista Árvore, Viçosa-MG, v.35, n.5, p.1061-1068, 2011 
Tabela 5 - Desvios da amostragem da abundância, área basal e volume por classe de diâmetro. Table 5 - Deviations of abundance sampling, basal area and volume by diameter class.

\begin{tabular}{|c|c|c|c|c|c|c|}
\hline \multirow[t]{2}{*}{ Classe de DAP } & \multicolumn{3}{|c|}{ Desvio absoluto } & \multicolumn{3}{|c|}{ Desvio relativo em \% } \\
\hline & Abundância & Área basal & Volume & Abundância & Área basal & Volume \\
\hline 45 & 0,39 & 0,06 & 0,38 & 11,78 & 11,54 & 9,97 \\
\hline 55 & 0,21 & 0,05 & 0,40 & 6,66 & 7,15 & 7,36 \\
\hline 65 & 0,02 & 0,00 & 0,05 & 1,03 & 0,42 & 0,90 \\
\hline 75 & 0,04 & 0,02 & 0,08 & 3,08 & 3,29 & 1,92 \\
\hline 85 & 0,01 & 0,01 & 0,08 & 1,70 & 1,76 & 2,92 \\
\hline 95 & 0,05 & 0,03 & 0,29 & 11,50 & 10,14 & 12,86 \\
\hline 105 & $-0,01$ & $-0,01$ & $-0,08$ & $-3,24$ & $-4,04$ & $-5,00$ \\
\hline 115 & 0,02 & 0,02 & 0,24 & 8,23 & 8,80 & 12,97 \\
\hline 125 & $-0,02$ & $-0,02$ & $-0,12$ & $-16,78$ & $-15,99$ & $-12,62$ \\
\hline 135 & 0,02 & 0,02 & 0,22 & 24,22 & 23,00 & 29,01 \\
\hline 145 & 0,00 & 0,00 & 0,02 & 7,14 & 7,30 & 4,19 \\
\hline 150 & 0,01 & $-0,03$ & $-0,19$ & 8,42 & $-10,51$ & $-8,42$ \\
\hline Total geral & 0,74 & 0,15 & 1,35 & 6,35 & 3,83 & 4,28 \\
\hline
\end{tabular}

geográfica das árvores possibilita melhor planejamento da exploração e consequente redução de gasto com máquinas (HOMES et al., 2002).

Embora as análises estatísticas realizadas não tenham identificado diferenças significativas entre a população real e a identificada na amostragem, as diferenças identificadas de volume e de número de espécies certamente não permitirão a substituição do Censo Florestal, tanto para a definição de contratos comerciais quanto para o licenciamento florestal pelos órgãos competentes. Dessa forma, a obrigatoriedade do inventário diagnóstico apenas onera o manejo florestal, tornando-o menos competitivo perante outros usos da terra, notadamente aqueles que carecem de desmatamento.

\section{CONCLUSÕES}

A intensidade amostral de $14 \%$ não foi suficiente para contemplar todas as espécies existentes na área. Embora a espécie de menor abundância tenha sido registrada, seis espécies das 60 existentes, isto é, 10\%, não foram registradas na amostra.

Os desvios observados por espécie, que variaram de mais de $600 \%$ para mais até $100 \%$ para menos, foram diluídos quando considerados os grupos. Nesse caso, a superestimação de algumas espécies foi compensada pela subestimação de outras, tornando o resultado mais próximo da realidade.

A compensação de desvios de uma espécie em relação à outra fez que os desvios fossem reduzidos em relação aos grupos de comercialização adotados pelo Serviço Florestal Brasileiro, embora tenham chegado a mais de $10 \%$ na abundância do Grupo 4 .

Com relação aos desvios por classe de diâmetro, os maiores observados foram os da abundância, que se concentraram na superestimação das classes inferiores.

Os desvios de estimativa de abundância, área basal e volume por espécie, apesar da alta intensidade amostral, indicam fragilidade de análises estruturais baseadas em inventários por amostragem.

O inventário florestal por amostragem tem muita utilidade para avaliação das florestas públicas para subsidiar pregões, como ocorre com as concessões florestais. Entretanto, em áreas privadas ele deveria voltar a ser uma opção, uma vez que o Censo Florestal, ou inventário a 100\%, já é obrigatório e indispensável à exploração florestal sustentável na região.

\section{AGRADECIMENTOS}

À Cia. de Compensados Triunfo, do Mato Grosso e do Acre; ao Valteir Costa; e ao Jáderson Mendes, pelas informações.

Ao Serviço Florestal Brasileiro, pelo apoio, com especial ênfase à Engenheira Florestal Anna Fanzeres.

\section{REFERÊNCIAS}

ARAÚJO, H. J. B. Inventário florestal a 100\% em pequenas áreas sob manejo florestal madeireiro. Acta Amazônica, v.36, n.4, p.447-464, 2006. 
BRASIL. Instrução Normativa $n^{\circ}$ 6, de 28 de dezembro de 1998. Estabelece as Diretrizes para o Manejo Florestal em escala Empresarial na Amazônia. Diário Oficial da República Federativa do Brasil, Brasília, DF, n. 250, 30 dez. 1998. Seção 1. p.152-153.

BRASIL. Norma de Execução n ${ }^{\circ}$ 1, de 24 de abril de 2007. Altera as normas técnicas para o manejo florestal na Amazônia. Diário Oficial da República Federativa do Brasil, Brasília, DF, n. 83, 2 maio 2007. Seção 1. p.91.

BRASIL. Instrução Normativa n ${ }^{\circ}$ 5, de 11 de dezembro de 2006. Altera as Diretrizes para o Manejo Florestal em escala Empresarial na Amazônia. Diário Oficial da República Federativa do Brasil, Brasília, DF, n. 238, 13 dez. 2006. Seção 1. p.155-158.

BRASIL. Resolução n ${ }^{0}$ 1, de 12 de maio de 2007. Altera o valor das madeiras nos Contratos de Transição, e dá outras providências. Diário Oficial da República Federativa do Brasil, Brasília, DF, n. 98, 12 maio 2007. Seção 1. p.58. Disponível em: <http:// www.mma.gov.br/estruturas/sfb/_arquivos/ resolucao_01_2007_precos_florestais.pdf $>$. Acesso em: 28 set. 2007.

CAVALCANTI, F. J. B.; MACHADO, S. A.; HOSOKAWA, R. T. Tamanho de unidade de amostra e intensidade amostral para espécies comerciais da Amazônia. Revista Floresta, v.39, n.1, p.207-214, 2009.

HIGUCHI, N. Amostragem sistemática versus amostragem aleatória em floresta tropical úmida. Acta Amazônica, v.16/17, p.393-400, 1987.

HIGUCHI, N.; SANTOS, J.; JARDIM, F. C. S. Tamanho de parcela amostral para inventários florestais. Acta Amazônica, v.12, n.1, p.93103, 1982.

HOMES, T. P. et al. Custos e benefícios financeiros da exploração florestal de impacto reduzido em comparação à exploração florestal convencional na Amazônia Oriental. Belém: Fundação Floresta Tropical, 2002. 69p.

HUSCH, B.; MILLER, C. I.; BEERS, T. E. Forest mensuration. 2.ed. New York: Ronald Press, 1972. 410p.

Revista Árvore, Viçosa-MG, v.35, n.5, p.1061-1068, 2011
MACHADO, S. A. Complete enumeration forest inventory versus cluster sampling method applied in the amazonic rain forest. Revista Floresta, v.18, n.1-2, p.122-130, 1988.

MACHADO, S. A.; FIGUEIREDO FILHO, A. Dendrometria. Curitiba: Universidade Federal do Paraná, 2003. 309p.

QUEIROZ, W. T. Técnicas de Amostragem em Inventário Florestal nos Trópicos. Belém: FCAP Serviço de Documentação e Informação, 1998. 147p.

QUEIROZ, W. T. Efeitos da variação estrutural em unidades amostrais na aplicação do processo de amostragem por conglomerados nas florestas do Planalto do Tapajós. 1977. 109f. Dissertação (Mestrado em Engenharia Florestal) -

Universidade Federal do Paraná, Curitiba, 1977.

QUEIROZ, W. T. Análise de fatores (Facttor analysis) pelo método de máxima verossimilhança: aplicação ao estudo de estrutura de florestas tropicais. 1984. 112f. Tese (Doutorado em Estatística Agronômica) - Escola Superior de Agricultura Luiz de Queiroz, Universidade de São Paulo, Piracicaba, 1984.

SILVA, J. N. M. Eficiência de diversos tamanhos e formas de unidades de amostras aplicadas em inventário florestal na região do Baixo Tapajós. 1980. 83f. Dissertação (Mestrado em Engenharia Florestal) - Universidade Federal do Paraná, Curitiba, 1980.

SOARES, C. P. B. et al. Comparação entre procedimentos de amostragem para espécies florestais raras e padrão de distribuição espacial agregado. Revista Árvore, v.33, n.3, p.545553, 2009.

SOUZA, D. R. et al. Análise estrutural em Floresta Ombrófila densa de terra firme não-explorada, Amazônia Oriental. Revista Árvore, v.30, n.1, p.75-87, 2006.

VIEIRA, S. Introdução à bioestatística. 4.ed. Rio de Janeiro: Campus, 2008. 360p.

ZAR, J. H. Biostatistical analysis. New Jersey: Prentice-Hall, 1999. 663p. 